Motrivivência $\quad$ v. $27, \quad$ n. $44, \quad$ p. $177-189$, maio/2015

\title{
ANÁLISE TÉCNICO-TÁTICA DO JOGO DA CAPOEIRA: contribuições para pensar a metodologia de ensino-aprendizagem-treinamento
}

Vinícius Thiago De Melo'

\section{RESUMO}

Este artigo teve por objetivo apresentar uma análise acerca da estrutura interna do jogo da capoeira e sua relação com as metodologias de ensino-aprendizagem-treinamento. Esta pesquisa realizou-se a partir da observação empírica como praticante e professor de capoeira e de revisão bibliográfica sobre a pedagogia do esporte e a capoeira. As análises se concentraram nos aspectos técnico-táticos do jogo, relacionando conceitos e princípios da pedagogia dos esportes à capoeira especificamente. Constatou-se que o jogo da capoeira pode ser classificado como sociomotor/coletivo, no entanto, este tem apresentado variações, podendo também ser classificado como psicomotor/ individual. Através da análise do jogo da capoeira realizada nesse artigo foi verificado que dificilmente um único método de ensino contemplaria todos os elementos técnicos e táticos envolvidos nessa atividade. Destacou-se, portanto, a importância de se utilizar metodologias múltiplas de ensino-aprendizagem-treinamento, as quais possam favorecer a preservação do jogo da capoeira a partir de seus fundamentos histórico-culturais, o qual se caracteriza pela "mandinga", "malícia", em outras palavras, um jogo técnico-tático que envolve imprevisibilidade, estratégia, improvisação, criatividade e tomada de decisão.

Palavras-chave: Jogo da Capoeira; Ensino-Aprendizagem-Treinamento; Pedagogia do Esporte 


\section{INTRODUÇÃO}

A capoeira é uma manifestação da cultura corporal que deve ser compreendida em seus aspectos histórico-culturais, sociológicos, antropológicos, técnico-tático e biológicos, como fora recomendado por Silva (2011, p. 890). Assim sendo, sem desconsiderar a importância dos referenciais histórico-culturais na conformação desse fenômeno, as análises desse artigo concentrar-se-ão sobre os aspectos técnico-táticos e metodológicos relacionados com o jogo corporal. Desse modo, a capoeira não será tratada aqui como uma modalidade esportiva, mas sim, como uma manifestação cultural que possui significativas similaridades com os esportes em função de um elemento comum, o jogo. Nessa perspectiva, o objetivo deste artigo é apresentar uma análise acerca da estrutura interna do jogo da capoeira e sua relação com as metodologias de ensino-aprendizagem-treinamento.

Apesar de estar amplamente difundida como atividade física-esportiva, sendo inserida em academias, clubes, escolas, projetos sociais e universidades, ainda é pequena a produção científica sobre a questão didático metodológica do processo de ensino-aprendizagem-treinamento desta modalidade específica. Assim, o professor / mestre de capoeira, muitas vezes, baseia-se em conhecimentos práticos e intuitivos para o ensino desta manifestação cultural. No que se refere ao campo das Ciências do Esporte (GARGANTA 2000; GRAÇA e
OLIVEIRA 1995; GRECO e BENDA 1998; KROGER e ROTH, 1999) registra-se significativos avanços sobre o fazer pedagógico do profissional que atua no ensino dos jogos esportivos coletivos.

Embora não haja muitas investigações científicas sobre a pedagogia da capoeira, considera-se importante relacionar conceitos, princípios, alternativas didáticas e metodológicas que se aplicam para o processo de ensino-aprendizagem-treinamento das modalidades esportivas em geral. Isto, por considerar que os jogos esportivos possuem características comuns ao jogo da capoeira, conforme será abordado ao longo deste artigo. É oportuno ressaltar que este estudo foi amparado por um amplo conhecimento prático que possibilitou uma importante observação empírica do autor ${ }^{2}$, o que foi muito significativo para relacionar os fundamentos teóricos e metodológicos da pedagogia do esporte ao jogo da capoeira.

Com base nas características das categorias de jogo esportivo apresentadas na classificação de Moreno (1994), o jogo da capoeira foi enquadrado como esporte de cooperação/oposição (sociomotor). No entanto, através da observação empírica a partir do trânsito por diversos contextos de prática e revisão bibliográfica (livros, artigos, documentários) específica acerca do jogo da capoeira, percebeu-se que este jogo apresenta significativas variações em função das diferentes concepções técnico-táticas de alguns professores / mestres. Sendo assim, observou-se que em alguns contextos de prática a estrutura interna deste jogo pode

2 O autor é professor de Capoeira com experiência na prática e ensino dessa atividade. Destaca-se a observação empírica em 19 anos de participação (1995 a 2014) em rodas, treinos, eventos/batizados e cursos de capoeira de diferentes Grupos da Grande Belo Horizonte e Minas Gerais, bem como outras cidades pelo país. 
estar alterada, apresentando características mais aproximadas da categoria de esporte individual (psicomotor), transformando o que antes era dotado de irreverência, surpresa, improvisação e imprevisibilidade, em espetacularização individual. Nesta perspectiva, o presente artigo chama a atenção para a necessidade de se refletir sobre a prática pedagógica da capoeira com vistas à resgatar este jogo que é essencialmente caracterizado pela "mandinga", a "malícia", em outras palavras, um jogo técnico-tático que envolve estratégia, imprevisibilidade e capacidades como percepção, atenção, concentração, antecipação e tomada de decisão.

\section{Classificação do jogo da capoeira}

Para se discutir os métodos de ensino em qualquer modalidade é imprescindível conhecer bem as características das mesmas. Segundo Garganta (2000, p. 52), "é necessário analisar a estrutura dinâmica interna de cada jogo, no sentido de configurar a especificidade". Uma das formas de iniciar o estudo sobre o jogo da capoeira é considerar possíveis formas de classificação desta atividade, para possibilitar sua diferenciação em relação às distintas estruturas deste jogo corporal.

$\mathrm{Na}$ tentativa de descrever os elementos e estruturas comuns aos esportes, Moreno (1994), baseado em Parlerbas (1981, apud MORENO, 1994), desenvolveu uma sequência lógica de raciocínio através de parâmetros que relacionam o uso do espaço e a forma de participação dos jogadores. Outro fator chave para a diferenciação dos esportes, segundo Moreno (1994), é o grau de incerteza presente na modalidade. Esportes individuais como salto em altura e ginástica artística, por exemplo, apresentam baixa interferência externa para o praticante, exigindo deste a utilização predominante da capacidade proprioceptiva. Já para outras categorias de esportes a incerteza sobre as condições do meio no qual realiza-se a atividade exige do praticante uma constante adaptação do seu comportamento motor à situação. Para esta categoria a dimensão da percepção de fatores externos possui importância de primeira ordem (MORENO, 1994). Com base neste parâmetro Moreno (1994) denominou dois grandes grupos de esportes: os psicomotores e sociomotores. Os primeiros podem ser considerados como aqueles em que o indivíduo atua sozinho (individualmente). Os últimos são aqueles que o indivíduo atua com o outro ou com os outros. Os esportes sociomotores podem ser subdivididos de acordo com o tipo de relação que os praticantes estabelecem entre si durante a realização da atividade, por exemplo: oposição, cooperação e cooperação-oposição.

O espaço disponível para execução de ações motoras pode apresentar interações simultâneas dos atacantes e dos defensores em relação ao objetivo do jogo. Assim, para a análise das ações nos jogos esportivos, também devem ser consideradas as relações existentes entre os companheiros, os adversários, e o meio ambiente. Nos jogos, as ações podem decorrer em espaços separados (ex: Queimada, Voleibol, Tênis de mesa) ou de uso comum (ex:Futebol, Handebol, Capoeira) para ambas as equipes ou jogadores. Em outra perspectiva, a participação dos mesmos pode ocorrer de forma simultânea (ex: Futebol, Handebol, Capoeira) ou alternada (ex: Sinuca, Xadrez, Voleibol, Tênis de mesa e etc). A figura 1 é um esquema elaborado para representar a relação entre companheiros, adversários e meio ambiente. 


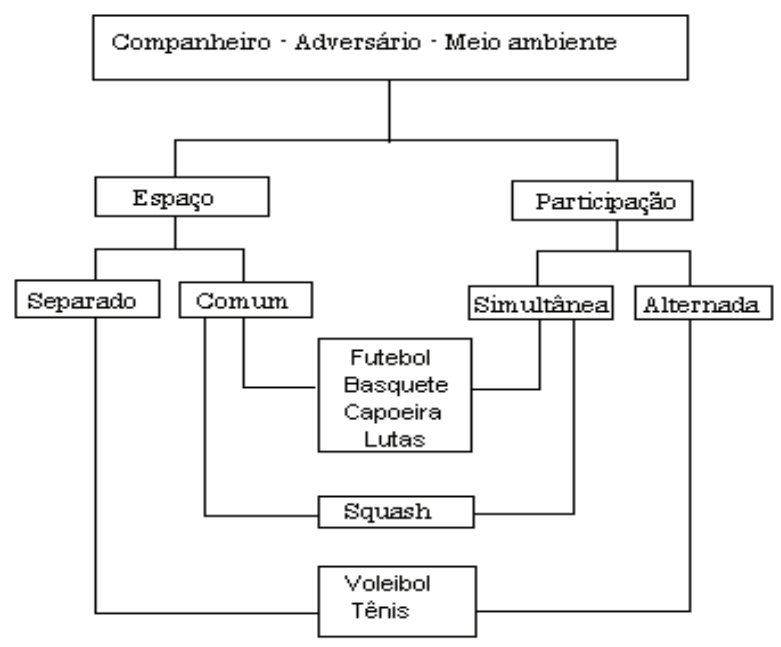

Figura 1: Classificação dos esportes cooperação/oposição (adaptado)

Fonte: MORENO, 1994

Considerando estes parâmetros, pode se dizer que a capoeira é uma modalidade de "cooperação-oposição" e "ação simultânea" que se desenvolve em espaço comum para os jogadores, com ações de defesa e ataque simultâneas, assim como nos esportes coletivos: futsal, Handebol, futebol e basquetebol. Assim sendo, considera-se que a definição de Greco (2001, p.48) acerca dos esportes coletivos pode se aplicar para o jogo da capoeira: "são atividades ricas em situações imprevistas que requisitam do praticante respostas variadas, velozes, precisas, complexas e muitas vezes, precisam ser realizadas com elevada pressão de tempo".

No entanto, apesar das semelhanças que levariam a modalidade a uma mesma forma de classificação, a capoeira possui uma característica particular, pois nos jogos esportivos coletivos a cooperação ocorre com os jogadores de uma mesma equipe (companheiro) e a oposição com a equipe adversária, ao passo que, na capoeira, a cooperação e oposição se dão com o próprio "adversário", de modo que os jogadores, em um mesmo jogo, ora estabelecem relações de cooperação ora de oposição. Pode-se dizer que a cooperação é imprescindível para o jogo da capoeira, pois caso os jogadores se oponham o tempo todo o jogo pode tomar o rumo de um confronto direto, como ocorre nos esportes de luta/ combate que são classificados por Moreno (1994) como jogos puramente de oposição. Essa classificação acerca do tipo de relação companheiros-adversários está representada na figura adaptada a seguir: 


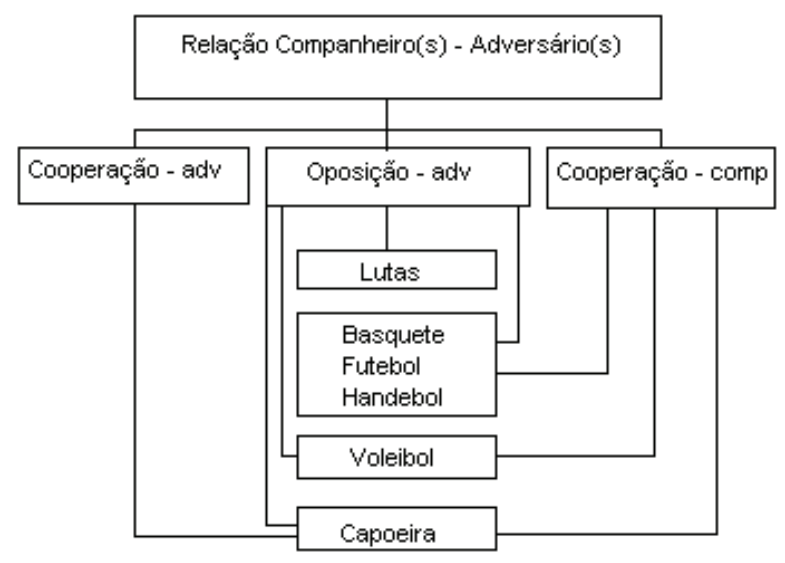

Figura 2: Classificação esportes sociomotores Relação companheiros(os) - adversários(os)

Fonte: MORENO, 1994

Esta cooperação com o adversário, peculiar à capoeira, ocorre em muitas situações de jogo, por exemplo, no movimento da bananeira ou aú, característico da capoeira, o jogador que aplica este movimento fica relativamente vulnerável, pois está apoiado somente pelos braços com as pernas para o ar. Se esta ação realiza-se em uma luta (em situação puramente de oposição), o lutador poderia ser facilmente superado pelo adversário que se aproveitaria desta situação. Mas, no jogo da capoeira, acertar o "adversário" nessa condição pode ser considerado como uma ação grosseira, pois a essência do jogo está no:

(...) desnorteamento do adversário por meio da malícia e da negaça. A estratégia do bom capoeira era tentar iludir o oponente com trejeitos de mãos e pés, envolvendo-o como a uma aranha na teia, até poder aplicar o golpe. No fundo, uma arte de sedução e engano do olhar do outro, cuja tônica não se definia pela pretensão a uma verdade identitária do corpo [como no boxe anglo-saxão, por exemplo], mas pela falsidade, isto é, pela tapeação do adversário" (SODRÉ, 2002, p. 48).

Além disso, na roda o "combate" também é artístico, plástico, portanto, os ataques também devem conter um sentido de beleza, e não pura e simplesmente o sentido de aniquilar o "adversário". Portanto, pode-se dizer que a capoeira depende de um código de ética entre os jogadores para que o jogo se desenvolva, pois caso contrário o jogo poderá ser reduzido a uma "briga de rua", em que o peso e força prevalecem sobre as habilidades técnico-táticas dos jogadores.

Vale lembrar, que a capoeira não é um esporte institucional com regras oficiais. Assim, esta conduta ética depende do bom senso e conhecimento filosófico sobre o que é o jogo da capoeira, ou, em 
outras palavras, quais são as "regras" desse jogo. Interessante que esta característica da modalidade em questão faz com que a imprevisibilidade do jogo seja ainda maior quando os capoeiristas da roda são desconhecidos, pois, o rompimento com a ética entre os jogadores, ou mesmo as diferentes éticas existentes em contextos de prática diferenciados, modificam as possibilidades de ação, sendo que o capoeirista visitante deve se portar com cautela, evitando se expor a eventuais atitudes agressivas. Portanto, a forma de jogar em diferentes rodas de capoeira deve variar, de modo que, em uma roda de amigos que se conhecem e se respeitam, as probabilidades de que as "regras de conduta" sejam desrespeitadas é muito menor.

Outra diferença importante entre a capoeira e os esportes coletivos é o fato de que os jogadores, em diversos momentos de uma partida estão "ociosos" por não estarem em contato direto com a bola. Na capoeira a dinâmica do jogo é diferente, sendo caracterizado por ser contínuo, de modo que a ação dos órgãos sensoriais é permanente em função das movimentações do companheiro estarem constantemente influenciando suas ações e intenções. Assim, no jogo da capoeira os jogadores estão frequentemente criando "saídas", "movimentos" que resolvam as "situações problema" as quais são colocadas pelo companheiro. Sodré (2002, p. 22) se refere a esta característica marcante da capoeira no trecho a seguir:

Na capoeira, tudo se passa sem esquemas nem planos preconcebidos. É o corpo soberano, solto em seu movimento, entregue ao seu próprio ritmo, que encontra instintivamente o seu caminho. Senhor do seu corpo, o capoeirista improvisa sempre e, como o artista, cria.
A diversidade nas possibilidades de respostas para as tarefas de um jogo foi mencionada por Graça e Oliveira (1995, p. 13) ao referir-se aos jogos esportivos: "No decurso de um jogo surgem tarefas motoras de grande complexidade para cuja resolução não existe um modelo de execução fixo". Portanto, a elevada variabilidade de situações inerentes aos jogos exige dos jogadores a capacidade de criar, improvisar. Esta capacidade foi descrita por Graça e Oliveira (1995, p. 12-13) como adaptabilidade “(...) os jogadores devem resolver situações de jogo que, dadas as diversas configurações exigem uma elevada adaptabilidade especialmente no que diz respeito à dimensão tático-cognitiva".

O comportamento tático no jogo, segundo Greco (2001), "significa capacitar-se a resolver com sucesso as tarefas ou problemas que a atividade the apresenta". $\mathrm{Na}$ capoeira as situações problema estão relacionadas com o objetivo do jogo, que, de modo geral, pode ser desequilibrar o companheiro ou aplicar um golpe certeiro em local desprotegido, demonstrando que só não bateu porque não quis. Vale ressaltar que tudo isso deve ser feito mais por "malícia", "mandinga", do que por força física. Mestre João Pequeno, discípulo do mestre Pastinha fala sobre isso em seu depoimento no filme "Pastinha! Uma Vida Pela Capoeira":

O capoeirista, pra bater no seu "adversário" ele não precisa encostar o pé, ele deve ter o seu corpo freado, manejado, pra ele levar o pé, ver que o adversário não se defendeu, antes do pé encostar ele freia, porque quem tá de parte vê: "ele não bateu porque não quis". Então não precisa dar pancada, pra bater não precisa de dar pancada no "adversário" (MURICY, s/d) 
No universo da capoeira a tática pode ser expressa pelas palavras "mandinga", "malícia". Estes termos se referem a um comportamento típico descrito por velhos mestres da capoeira baiana, como nos revela Vieira (1998, p. 111) a seguir:

\begin{abstract}
A "mandinga" aparece como o estruturante central, o componente que atribui a verdadeira identidade ao jogo da capoeira. No contexto da capoeira, o termo mandinga designa (...) a malícia do capoeirista durante o jogo, fazendo fintas, fingindo golpes e iludindo o adversário, preparando-o para um ataque certeiro (...) (VIEIRA, 1998, p. 111).
\end{abstract}

Vale ressaltar que o termo "mandinga" se confunde com a "malícia" que, por sua vez, refere-se à tática do capoeirista. No trecho a seguir Capoeira (1985, p. 90) explicou como a malícia pode representar um fundamento tático do capoeirista:

Malícia era o que fazia um capoeirista prever o que o outro ia fazer e, por outro lado, enganá-lo fingindo que se vai fazer algo quando na verdade está se armando uma arapuca. Por exemplo: um jogador está de pé e o outro se movimenta no chão. O que está de pé finge que vai sair num aú bem aberto e sai mesmo, numa distância tal do jogador de chão, que este não resistirá entrar numa cabeçada. É então que o jogador que saiu no aú completa sua jogada dando uma chibata no atacante. Ou seja, ele "abriu" o jogo para chamar o ataque do outro e, já prevendo como seria o ataque, tinha o contragolpe prontinho. Isso é malícia em capoeira.

Nessa colocação percebe-se claramente a capacidade tática de antecipação, em que o capoeirista experiente, ciente de um comportamento típico no jogo da capoeira, induziu uma ação do oponente para antecipar-se e levar vantagem sobre ele. Assim, na capoeira, a dimensão tático-cognitiva pode ser entendida como uma complexa teia de situações em um ambiente dinâmico, que exigem dos jogadores capacidades como percepção, atenção, concentração, antecipação e tomada de decisão. É através destas capacidades bem desenvolvidas que o capoeirista age com "malícia", percebendo os "sinais relevantes", prevendo as situações e agindo na tentativa de "enganar", surpreender, iludir para tentar levar algum tipo de vantagem sobre o outro, colocando-o em situação vulnerável como forma de superação de um jogador sobre o outro.

\section{Variações do jogo da capoeira contem- porânea}

Outra característica do jogo da capoeira muito importante consiste na interação entre os jogadores. Ao longo da história da capoeira movimentos foram introduzidos, dentre eles movimentos acrobáticos de grande beleza e complexidade. $\mathrm{Na}$ verdade não existem movimentos que não possam ser executados na roda, no entanto, o que acontece é que, ultimamente, os capoeiristas se "esquecem" de jogar com o outro para exibir a performance dos seus movimentos quase que individualmente.

Falcão (1995) chama a atenção para a influência que o sistema vigente vem exercendo sobre o movimento humano, que o transforma em mercadoria, seguindo padrões estéticos que fazem com que a modalidade em questão tome contornos diferenciados, reduzindo-a a shows e exibições, de forma que os movimentos dos dois jogadores não se articulam. Segundo 
este autor "O movimento corporal humano não deve ser entendido como qualquer movimento feito sem reflexão, mas sim pensado, analisado, criticado e contextualizado" (FALCAO,1995 p. 13).

Nesta perspectiva, em que a capoeira tem se expandido pelo Brasil e pelo mundo (FALCÃO, 2006), muitas vezes seus vetores são influenciados pelas tendências da sociedade do espetáculo. Nesse processo, muitos mestres e professores introduziram movimentos complexos e metodologias de ensino-aprendizagem-treinamento pouco comprometidas com a estrutura interna do jogo da capoeira. Assim sendo, Falcão (2006, p. 72) define a capoeira contemporânea:

Como construção social, que permanentemente se manifesta, e como manifestação cultural que permanentemente se constrói, o jogo da capoeira é influenciado pelo tempo histórico em que se situa, e também, edificado a partir dos interesses e das ações dos sujeitos que, por meio dele, atuam e disputam poder na sociedade. Se, outrora ele era carregado de irreverência, surpresa, malícia, improvisação e imprevisibilidade, atualmente ele tem se apresentado mais sintonizado com outras categorias típicas do ideário neoliberal, como espetacularização, racionalização, competição e performance.

Nessa direção, a ressignificação do jogo da capoeira pode ser visualizada quando os dois jogadores fazem uma exibição individual utilizando espaços diferentes dentro da roda. A identificação dessa situação pode ser verificada a partir do aumento no tamanho da roda de capoeira, o que proporciona esse distanciamento entre os jogadores, os quais posicionam-se completamente fora do raio de ação um do outro, não sendo necessário nem mesmo se preocupar em esquivar do golpe do companheiro. Neste formato o jogo não depende da utilização dos órgãos perceptivos, a não ser os proprioceptivos. Esta ressignificação altera profundamente a estrutura interna do jogo, de forma que este adquire características que se aproximam mais da categoria de jogo psicomotor ou individual (MORENO, 1994). Isto porque o espaço para a realização do jogo passa a ser separado, e a oposição entre os jogadores cede lugar para uma relação exclusivamente de cooperação.

\section{O jogo da capoeira e as metodologias de ensino-aprendizagem-treinamento}

Provável que a ressignificação observada a partir da análise sobre a lógica interna do jogo da capoeira seja decorrente do processo de expansão da capoeira em academias, clubes e escolas, o que tem provocado a introdução de movimentos complexos e metodologias sem considerar os fundamentos originais do jogo da capoeira. Nessa direção, Capoeira (1999) comentou a influência que as aulas de capoeira receberam das ginásticas suecas, as quais são caracterizadas pela racionalidade que privilegia a formação retilínea e monotonia em exercícios de repetição exaustiva de movimentos. Nesta perspectiva, Moreno (2003) chama atenção para o antagonismo entre o jogo da capoeira e este tipo de metodologia denominada como analítica (GRECO e BENDA, 1998), a qual vem sendo amplamente aderida entre professores e mestres de capoeira da contemporaneidade.

Avesso [método analítico e a capoeira] não por ser boa ou má sob uma determinada perspectiva, mas porque valorizam, 
cada uma, o seu oposto. O baixo e o alto, o olhar fixo e fulminante e o olhar no horizonte, o círculo e a reta, a ginga e a retidão, o fixo e o nômade, a previsibilidade e a imprevisibilidade, a simulação e a dissimulação, a coreografia expontânea e a coreografia ensaiada, o mundo de "pés no chão" e o mundo "de pernas pro ar". Duas atividades que são gramaticalmente diferentes, gerando portanto, diferentes sintaxes corporais." (MORENO, 2003, p. 61)

Desse modo, Graça e Oliveira (1995) acrescenta uma crítica a obsessão que se apresenta nos processos de ensino-aprendizagem-treinamento centrados na técnica individual, que, segundo ele, realizara uma transposição direta dos métodos utilizados em esportes individuais (natação e atletismo) sem considerar a especificidade estrutural e funcional de cada modalidade.

Assim, neste contexto, o professor/ mestre de capoeira poderá refletir sobre qual é a categoria de capoeira que está ensinando ou pretende ensinar (psicomotora ou sociomotora), para que, a partir daí faça a seleção da metodologia que contribua para seus objetivos. Entretanto, acredita-se ser importante eleger métodos que possam favorecer a preservação do jogo da capoeira a partir de seus fundamentos histórico-culturais, o qual se caracteriza pela "mandinga", a "malícia”, em outras palavras, um jogo tático que envolve muita estratégia, criatividade, improvisação e imprevisibilidade. Desse modo, "a ação de jogar é fruto do diálogo e, para que eu possa jogar com o outro, tenho de estabelecer uma relação dialógica, porque senão, sai de uma relação de mão e contramão, para trafegar numa relação unilateral" (CASTRO, 2002, p. 94).

Considera-se, portanto, que uma importante característica do jogo da capoeira está relacionada com a imprevisibilidade, que exige dos jogadores uma ininterrupta ativação perceptiva em função do grande número de possibilidades de ações inesperadas. Sendo assim, os jogadores estão frequentemente criando e recriando "saídas" para as "situações problema" apresentadas pelo companheiro. Nesse contexto, a capacidade de criatividade / improvisação se apresenta como imprescindível para o capoeirista. Essa capacidade foi descrita por Graça (1995) como adaptabilidade. Para o desenvolvimento dessa capacidade considera-se importante que sejam adotados métodos de ensino-aprendizagem-treinamento específicos.

Recorrendo-se às pesquisas da pedagogia dos esportes foi possível encontrar metodologias voltadas para o desenvolvimento desta capacidade. Greco e Benda (1998) apresentaram a metodologia situacional que consiste em jogadas básicas extraídas de situações padrão de jogo. Esse método parte do pressuposto de que cada jogo possui situações padrão típicas, como por exemplo, a rasteira na capoeira; o lançamento no handebol; o chute no futebol; a cortada no voleibol e etc. Estas situações podem, às vezes, não abranger a ideia total do jogo, porém elas têm o elemento central do mesmo. De acordo com Greco (1997, p. 51) no treinamento situacional, "devem ser apresentadas situações padronizadas, ou seja, exercícios em complexo, em que seja fundamentalmente exigido do aluno que este proceda à tomada de decisão para resolver a tarefa". A tomada de decisão, portanto, se refere à criação do capoeirista. Nessa direção, o método situacional tem a vantagem de inter-relacionar a técnica e a tática, contribuindo para que o aprendiz tenha maior consciência sobre as funções 
táticas das técnicas praticadas durante as aulas/treino, favorecendo a tomada de decisão pela utilização dos recursos de antecipação e percepção de sinais relevantes das situações de jogo.

Nesse sentido, Greco (1998) acrescenta que "a função de toda metodologia de ensino-aprendizagem-treinamento é proporcionar ao indivíduo os meios, caminhos e ferramentas que facilitem e tornem possível a obtenção de um novo nível de rendimento". Para isto, o professor poderá recorrer a diferentes formas metodológicas, em que, a escolha do método adequado é um dos mais importantes aportes pedagógicos que o docente pode oferecer aos seus alunos. Assim, a metodologia utilizada deve considerar aspectos como as características do jogo, o nível de maturação do praticante, as capacidades coordenativas e a motivação.

\section{CONSIDERAÇÕES FINAIS}

$\mathrm{Na}$ tentativa de identificar as características, estrutura e elementos do jogo da capoeira recorreu-se à classificação dos esportes descrita por Moreno (1994) que utilizaram parâmetros dos quais relacionam o uso do espaço, a forma de participação dos jogadores e o grau de incerteza (variabilidade) presente no jogo.

Em um primeiro momento, a capoeira foi enquadrada na categoria de cooperação-oposição e ação simultânea com a característica particular de que a cooperação ocorre com o próprio "adversário". No entanto, observam-se profundas transformações que a capoeira vem sofrendo em sua estrutura, de forma que o espaço delimitado para o jogo seja separado, não havendo nenhum tipo de oposição entre os jogadores. Neste formato o jogo deixa de ser caracterizado como um jogo sociomotor passando a estar enquadrado pela categoria de esporte individual ou psicomotor. Pode-se dizer que esta descaracterização reduz o jogo da capoeira, que antes dotado de irreverência, surpresa, malícia, improvisação e imprevisibilidade, agora, reduzido a espetacularização individual.

A partir da análise do jogo da capoeira realizada nesse artigo foi possível constatar que dificilmente um único método de ensino contemplaria todos os elementos técnicos e táticos que estão envolvidos em um jogo tão complexo como esse. Acredita-se, portanto, que "não é possível que um jogo nas suas diversas e complicadas situações técnico-táticas e psicológicas-sociais, seja aprendido pelo aluno sem que paralelamente se trabalhe com uma metodologia mista, múltipla, que assuma a necessidade de aquisição das mais variadas experiências de jogo" (GRECO, 2001, p. 51).

\section{REFERÊNCIAS}

ADORNO, Camille. A Arte da Capoeira. Goiânia/ GO. ed. Kelps, 1999.

CASTRO, Luís Vitor Júnior; SOBRINHO, José Sant'anna. O Ensino da Capoeira por uma Prática Nagô. Revista Brasileira de Ciências do Esporte. Campinas, v.23, n.2. Editora Autores Associados, jan. 2002.

CAPOEIRA, Nestor. Capoeira os Fundamentos da Malícia. Rio de Janeiro: Record, 1999.

CAPOEIRA, Nestor. Galo Já Cantou, Capoeira para Iniciados. Rio de Janeiro: Cabicieri Editorial, 1985.

FALCÃO, José Luiz Cirqueira. Capoeira 
e/na Educação Física. Revista Sprint. n. 79 p. 10-14, 1995.

$$
\text { . O Jogo da Capoeira em }
$$

Jogo. Revista Brasileira de Ciências do Esporte. v. 27, n. 2, p. 59-74, 2006.

\section{A capoeira é do Brasil? A}

capoeira no contexto da globalização. In: Seminário Internacional Educação Intercultural, Movimentos sociais e sustentabilidade, 3., e Colóquio da Association Pour La Rcherche Interculturelle (ARIC) na América Latina, 1, 2006. Pesquisado em 25 de setembro de 2011. Disponível em http:// www.portalcapoeira.com acesso em 15/09/2011.

GARGANTA, Julio. Horizonte Orbitas: No Treino dos Jogos Desportivos. Universidade do Porto, Centro de Estudos dos Jogos Desportivos, Ed. Julio Garganta, 2000.

GRAÇA, Amândio; OLIVEIRA, José. O Ensino dos Jogos Desportivos. Ed. Amândio Graça, José Oliveira, 1995.

GRECO, Pablo Juan. Sistematização do processo de ensino-aprendizagemtreinamento tático nos jogos esportivos coletivos. In: GARCIA, Emerson S. et al. Temas Atuais em Educação Física e Esportes II. Belo Horizonte, p. 45-56, Health, 1997.

GRECO, Pablo Juan; BENDA, Rodolfo Novellino, organizadores. Iniciação Esportiva Universal. v. 1 Ed. UFMG, 1998.

GRECO, Pablo Juan, organizador. Iniciação Esportiva Universal. 308p. v. 2. Ed. UFMG, 1998.

GRECO, Pablo Juan. Métodos de ensinoaprendizagem-treinamento nos jogos esportivos coletivos. In: GARCIA,
Emerson S. et al. Temas Atuais em Educação Física e Esportes VI. Belo Horizonte p. 48-72, Saúde, 2001.

GRECO, Pablo Juan. O ensino-apredizagemtreinamento dos esportes coletivos: uma análise inter e transdisciplinar. In: GARCIA, Emerson S. el al. Temas Atuais em Educação Física e Esportes VII. Belo Horizonte, p. 53-78, Health, 2002. KROGER, Christian et al. Escola da Bola: um $A B C$ para iniciantes nos jogos esportivos. São Paulo. Phorte, 2002.

MORENO, Andrea. O Rio de Janeiro e o Corpo do Homem Fluminense: o "Não Lugar" da Ginástica Suéca. Revista Brasileira de Ciências do Esporte, Campinas, v. 25, n. 1, p. 55-68. Ed. CBCE, set. 2003.

MORENO, J. H.: Análisis de las Estructuras del Juego Deportivo. Inde Publicaciones: Zaragoza, 1994.

MURICY, Tereza S. Pastinha: Uma Vida Pela Capoeira. Christal Rio Produções Cinematográficas LTDA. Ed. Paulo Humberto, Alexandre e Ivan Sovano, s/d. PARLERBAS, P. Pour une Education Physique Structural, em EPS, n. 92. 1968. apud MORENO, J. H.: Análisis de las Estructuras del Juego Deportivo. Inde Publicaciones: Zaragoza, 1994. REGO, Waldeloir. Capoeira Angola: Ensaio Sócio Etnográfico. Salvador: Itapuã, 1968.

SILVA, Paula Cristina da Costa. Capoeira nas aulas de Educação Física: alguns apontamentos sobre processos de ensino-aprendizado de professores. Revista Brasileira Ciências do Esporte, Florianópolis, v. 33, n. 4, p. 889-903, out./dez., 2011. 
SODRÉ, Muniz. Mestre Bimba: corpo de mandinga / organização Waly Salomão, Maria Vitória de Seixas Caldas. Rio de Janeiro: Manati, 2002.
VIEIRA, Luiz Renato. O Jogo da Capoeira: Corpo e Cultura Popular no Brasil. Sprint, 1998.

TECHNICAL-TACTICAL ANALYSIS OF CAPOEIRA GAME: contributions to think the teach-learning-training metodology

\begin{abstract}
The aim of this article is presented a analysis on the internal structure of capoeira game in your relation with teach-learning-training methodologies. This research took place from empirical observation and literature review. The analysis focused on the technical and tactical aspects of the game, relating concepts and principles of sports pedagogy to capoeira specifically. It was noted that the game of capoeira can be classified as sociomotor/collective, however, this has presented variations, and can also be classified as psychomotor/individual. Through the analysis of the capoeira game performed in that article was verified that hardly a single teaching method would address all the technical and tactical elements involved in this activity. Therefore, was detach the importance of using multiples methods of teaching-learning-training, which might facilitate the rescue of the capoeira game from their historical-cultural foundations, which is characterized by "mandinga", "malice", in other words, a technical-tactical game which involves unpredictability, strategies, improvisation, creativity and decision-making.
\end{abstract}

Keywords: Capoeira Game; Theach-Learnig-Training; Sports Pedagogic

ANÁLISIS TÉCNICO-TATICO DEL JUEGO DE LA CAPOEIRA: contribuiciones al pensamento acerca de la metodologia de enseñanza-aprendizaje-formación

\title{
RESUMEN
}

Este artículo presenta un análisis sobre la estructura interna del juego de la capoeira en su relación con de la metodología de enseñanza-aprendizaje-formación. Esta investigación Ilevó a cabo de la observación empírica y revisión bibliográfica. El análisis se centró en los aspectos técnicos y tácticos del juego, relativa conceptos y principios de la pedagogía del deporte en el capoeira específicamente. Se observó que el juego de la capoeira se puede clasificar como sociomotor/colectivo, sin embargo, esto ha presentado variaciones, y también se puede clasificar como psicomotor/individual. A través de la análisis del juego de la capoeira realizado en ese artículo se verificó que apenas un único método de enseñanza no abordaría todos los elementos técnicos y tácticos involucrados en esta actividad. Por tanto, destacaron la importancia de utilizando múltiples metodologías de 
V. $27, \mathrm{n}^{\circ} 44$, maio/2015

enseñanza-aprendizaje-formación, que puede promover la preservación del juego de la capoeira desde sus fundamentos histórico-cultural, que se caracteriza por "Mandinga", "malicia", en otras palabras, un juego técnico-táctico que implica la imprevisibilidad, estrategias, improvisación, creatividad y toma de decisiones.

Palabras clave: Juego de la Capoeira; Enzañana-Aprendizaje-Formación; Pedagogia del Desporte

Recebido em: outubro/2014

Aprovado em: março/2015 